\title{
Ultraviolet Sensitivity, Spontaneous Mutability and DNA Degradation in Escherichia coli Strains Carrying Mutations in $u v r$ and rec Genes
}

\author{
By G. B. SMIRNOV, E. V. FILKOVA AND A. G. SKAVRONSKAYA \\ The Gamaleya Institute for Epidemiology and Microbiology, AMS USSR, Moscow, U.S.S.R.
}

\author{
(Received I9 December 1972; revised 6 February 1973)
}

\begin{abstract}
SUMMARY
Escherichia coli $u v r 502$ bacteria have a higher spontaneous mutability and are 4.6 times more u.v.-sensitive than isogenic wild-type bacteria. Bacteria deficient in dimer excision ( $u v r A 6)$ are 15 times more u.v.-sensitive than isogenic $u v r A^{+}$ bacteria. Double mutant uvrA6uvr502 bacteria are only I.5 times more u.v.sensitive than $u v r A 6$ bacteria and double mutant $u v r 502$ rec $A 56$ bacteria were as u.v.-sensitive as rec $A 56$ bacteria, suggesting that there exists a $u v r A^{+-}$and $r e c A^{+}$dependent repair pathway which is blocked by the uvr502 mutation. We suggest that the uvr 502 mutation affects primarily the excision repair pathway. Strict additivity of the $u v r 502$ and $\operatorname{recB2I}$ mutations on u.v. sensitivity suggests that rec $B^{+}$-mediated repair acts in part of repair pathway different from excision repair. U.v.-induced DNA degradation in the uvr 502 bacteria is only slightly greater than that in $u v r^{+}$bacteria and the uvr502 mutation does not affect the 'reckless' character of u.v.-induced DNA breakdown in the recA56 bacteria. The uvr502$u v r A 6$ and $u v r 502$ rec $A 56$ or uvr502 recB2I double mutants have spontaneous mutation frequencies similar to that of the single uvr5oz strain.
\end{abstract}

\section{INTRODUCTION}

The rate of spontaneous mutability is determined genetically and mutator genes controlling this property in various bacterial and viral species have been described (e.g. Drake, I969; Liberfarb \& Bryson, I970). In some cases the changes in spontaneous mutability were coupled with u.v. sensitivity (e.g. Smirnov, Filkova \& Skavronskaya, 1972). These observations lead to the hypothesis that mechanisms of DNA repair are also involved in the determination of the spontaneous mutation rates. So far, however, unequivocal evidence that both mutator effect and u.v. sensitivity in bacteria are due to a single mutation have been presented only in few cases (Böhme, 1969; Smirnov et al. 1972; Siegel, 1973) and the mechanisms of action of the mutator genes as well as the modes of their involvement in DNA repair remain obscure.

We have found an increased frequency of spontaneous mutation in the u.v.-sensitive Escherichia coli mutant uvr 502 (Smirnov \& Skavronskaya, 1968) and shown that both u.v. sensitivity and the mutator property of the mutant are recessive and determined by the single mutation uvr502 (Smirnov et al. 1972) which has been mapped between ilv and metE loci on the E. coli genetic map (Smirnov \& Skavronskaya, 197I). Similar results were obtained elsewhere (Mattern, I97I). The function affected in the uvr502 mutant appears to be essential not only for maintenance of low mutability and DNA repair but also for the viability of $E$. coli lacking DNA polymerase I (Mattern, I97I; Smirnov et al. 1973).

In this paper we describe some properties of double mutants containing uvr502 and other 
Table I. Bacterial strains*

Relevant genetic character

\begin{tabular}{|c|c|c|c|c|c|c|c|c|}
\hline Strain & Sex & $u v r A$ & $u v r(502)$ & rec & thy $A$ & met $E$ & Str. & Source \\
\hline $\mathrm{KSIO} 2$ & $\mathrm{~F}^{-}$ & + & + & A56 & + & - & $\mathrm{R}$ & \\
\hline KSIO5 & $\mathbf{F}^{-}$ & + & + & + & + & - & $\mathrm{R}$ & \\
\hline KSIO6 & $\mathrm{F}^{-}$ & + & - & + & + & - & $\mathbf{R}$ & \\
\hline KS 107 & $\mathbf{F}^{-}$ & + & - & A56 & + & - & $\mathrm{R}$ & \\
\hline KSII 2 & $\mathrm{~F}^{-}$ & + & + & + & - & - & $\mathbf{R}$ & \\
\hline KS I I 3 & $\mathrm{~F}^{-}$ & 6 & + & + & - & - & $\mathrm{R}$ & This paper \\
\hline KSII 4 & $\mathrm{~F}^{-}$ & + & - & + & - & - & $\mathbf{R}$ & \\
\hline KSII 5 & $\mathrm{~F}^{-}$ & 6 & - & + & - & - & $\mathbf{R}$ & \\
\hline KSI 29 & Hfr & + & + & + & + & - & $\mathrm{R}$ & \\
\hline KSI3O & $\mathrm{Hfr}$ & + & + & $B 2 I$ & + & - & $\mathbf{R}$ & \\
\hline KSI3I & $\mathrm{Hfr}$ & + & - & + & + & - & $\mathbf{R}$ & \\
\hline KSI 32 & Hfr & + & - & $B 2 I$ & + & - & $\mathbf{R}$ & \\
\hline
\end{tabular}

* Nomenclature conforms in most ways to the recommendations of Demerec, Adelberg, Clark \& Hartman (1966) except that the minus sign is used with the gene symbol to indicate a general mutant allele when the specific allele number is not required. The gene symbols are those recorded by Taylor (1970).

$u v r$ and rec mutations in an attempt to determine the repair pathway affected by the $u v r 502$ mutation and the possible influence of mutations in $u v r A$ or rec genes on the spontaneous mutability of the uvr 502 mutant.

\section{METHODS}

Bacterial strains. The strains used are described in the Table I or in the text.

Media. Bacteria were grown in L-broth (Difco tryptone, Io g; Difco yeast extract, $5 \mathrm{~g}$; $\mathrm{NaCl}, 5 \mathrm{~g}$; distilled water to I l) supplemented with $2.5 \times 10^{-3} \mathrm{M}-\mathrm{CaCl}_{2}$. Viable counts after u.v. irradiation were performed on $1.5 \%(\mathrm{w} / \mathrm{v})$ Difco nutrient agar plates (NA plates). In the experiments with DNA degradation bacteria were grown in glucose salts medium A (Davis \& Mingioli, 1950) supplemented with $0.25 \%$ (w/v) Difco Casamino acids (CAA medium). Glucose salts medium A supplemented with appropriate amino acids and solidified with $\mathrm{I} \cdot 5 \%(\mathrm{w} / \mathrm{v})$ Bactoagar Difco (A agar) was used also as selective plating medium for $\mathrm{Hfr} \times \mathrm{F}^{-}$crosses, $\mathrm{PI}_{\mathrm{I}}$ transduction, and determination of spontaneous mutability. Amino acids and thymine were added to the medium at a final concentration of $20 \mu \mathrm{g} / \mathrm{ml}$, and streptomycin at $200 \mu \mathrm{g} / \mathrm{ml}$.

Conjugation. Exponential-phase Hfr donor bacteria grown in Penassay broth (Difco) without shaking and $\mathrm{F}^{-}$recipients grown in the same medium with shaking were mixed in appropriate volumes to obtain a final ratio of donors to recipients of approximately $\mathrm{I}: \mathrm{ro}$ and incubated $40 \mathrm{~min}$ at $37^{\circ} \mathrm{C}$. Diluted samples were spread on to selective plates containing streptomycin and incubated at $37^{\circ} \mathrm{C}$ for $48 \mathrm{~h}$.

Transduction was carried out as described previously (Smirnov et al. 1972).

Selection of Valr mutants was performed on A agar supplemented with $100 \mu \mathrm{g} / \mathrm{ml}$ of DL-valine as described previously (Smirnov et al. I972).

U.v. irradiation. Stationary phase cultures of the strains KSIII to KSII 5 and KSI 29 to KSI32 or logarithmic cultures of the strains KSI02, KSI05, KSIO6 and KSIO7 grown in Lbroth were washed twice, resuspended in physiological saline to a density of $10^{7}$ bacteria $/ \mathrm{ml}$ and $5 \mathrm{ml}$ of suspension was irradiated with $254 \mathrm{~nm}$ of light from a BUV-I 5 germicidal lamp in the Petri dish ( $90 \mathrm{~mm}$ diam.) with constant stirring. An incident u.v. exposure rate of I $\mathrm{erg} / \mathrm{mm}^{2} / \mathrm{s}$ was used for u.v.-sensitive strains and of $3.6 \mathrm{ergs} / \mathrm{mm}^{2} / \mathrm{s}$ for u.v.-resistant strains. 
Gamma-ray treatment. To measure gamma-ray sensitivity suspensions containing $10^{7}$ bacteria/ml were spotted on to the surface of NA and irradiated with $25 \mathrm{krads}$ in a ${ }^{60} \mathrm{Co}$ source. Strains resistant to gamma-rays gave confluent growth in the drop area after $24 \mathrm{~h}$ of incubation at $37^{\circ} \mathrm{C}$ while gamma-ray-sensitive bacteria failed to grow after irradiation.

Measurement of DNA degradation. Cultures grown overnight in CAA medium were washed once, resuspended to a density of $10^{7}$ bacteria/ml in fresh CAA medium supplemented with Io $\mu \mathrm{Ci} / \mathrm{ml}(9 \mu \mathrm{g} / \mathrm{ml})$ of $\left[{ }^{3} \mathrm{H}\right.$-methyl]thymidine, $5 \mu \mathrm{g}$ unlabelled thymidine $/ \mathrm{ml}$ and $100 \mu \mathrm{g}$ deoxyadenosine $/ \mathrm{ml}$ and incubated at $37^{\circ} \mathrm{C}$ with shaking. After $2 \mathrm{~h}$ the bacteria were washed by centrifugation, resuspended in $\mathrm{I}$ o $\mathrm{ml}$ of fresh prewarmed CAA medium lacking glucose to a density of $10^{7}$ bacteria/ml and irradiated with u.v. light. After irradiation glucose (to $0.4 \%, \mathrm{w} / \mathrm{v}$ ) was added, the cultures were incubated at $37^{\circ} \mathrm{C}$ with shaking and I $\mathrm{ml}$ samples were pipetted at intervals into I $\mathrm{ml}$ of ice-cold Io \% trichloroacetic acid (TCA). After standing in ice for $20 \mathrm{~h}$ the samples were filtered through nitrocellulose filters, Hufs (Chemapol CSSR, Prague) washed twice with $4 \mathrm{ml}$ of ice-cold $5 \%$ TCA, placed in scintillation vials and dried prior to the addition of scintillation liquid (4 $\mathrm{g}$ PPO, $0 . \mathrm{I} g$ POPOP, toluene to I 1). Samples were counted in an Intertechnique Scintillation Counter SL 40. The loss of cold TCA precipitable radioactivity during post-irradiation incubation from the cultures labelled by $\left[{ }^{3} \mathrm{H}\right]$ thymidine was used as the measure of DNA breakdown.

\section{Construction of bacterial strains}

\section{RESULTS}

Sets of strains, isogenic except for uvrA6, uvr502 or recB2I mutations or approximately isogenic except for $u v r 502$ or recA 56 alleles were constructed in four similar but not identical genetic backgrounds.

Construction of the uvrs02recA56 double mutant, its component single mutants and $u v r^{+}$recA $^{+}$strain. Strains KSIO2, KSIO5, KSIO6 and KSIO7 were constructed by conjugation as follows. Strain $\mathrm{KS}_{5} 2 \mathrm{~F}^{-} u_{v r^{+}}$rec $^{+}$thy A 324 arg Alac YI4rhametEStr ${ }^{\mathrm{r}}$ was crossed with the donor strain JC5088 (Hfr KLI6) recA56 thr30oilv318 spc30oStr ${ }^{\mathrm{s}}$ and $\left.\mathrm{Thy}^{+} \mathrm{Arg}^{+}{ }^{+} \mathrm{Str}^{\mathrm{r}}\right]$ derivatives were selected. One of the u.v.-sensitive (UVs) and gamma-ray-sensitive $\left(\mathrm{X}^{\mathrm{s}}\right)$ derivatives obtained in the cross was designated KSIO2, and one of the u.v.-resistant (UVr) and gamma-ray-resistant $\left(\mathrm{X}^{\mathrm{r}}\right)$ derivatives was designated $\mathrm{Ksi05}$.

Strain KsIo6 is an $\mathrm{UV}^{s} \mathrm{X}^{\mathrm{r}} \mathrm{Thyy}^{+} \mathrm{Arg}^{+}\left[\mathrm{Str}^{\mathrm{r}}\right]$ derivative and the strain $\mathrm{KsIO}^{2}$ is an $\mathrm{UV}^{\mathrm{s}} \mathrm{X}^{\mathrm{s}}$ $\mathrm{Thy}^{+} \mathrm{Arg}^{+}\left[\mathrm{Str}^{\mathrm{r}}\right]$ derivative obtained in the cross of the uvr502 strain KSIO3 (isogenic with Ks52 except for the uvr502 mutation) with the same donor strain JC5088. Proof of the presence of both $u v r 502$ and recA56 mutations in the chromosome of the presumed double mutant $\mathrm{KSIO}_{7}$ was obtained by using this strain as transductional donor and the $i l v$ strain MM300 and cysC strain JC29I5 as recipients. Out of selected Ilv ${ }^{+}$transductants of MM300 $17 \%$ were $\mathrm{UV}^{\mathrm{s}} \mathrm{X}^{\mathrm{r}}$ and $6 \%$ of selected $\mathrm{Cys}^{+}$transductants of JC29I 5 were $\mathrm{UV}^{\mathrm{s}} \mathrm{X}^{\mathrm{s}}$. The cotransduction of the $\mathrm{UV}^{\mathrm{s}}$ character with $i l v^{+}$and the $\mathrm{UV}^{\mathrm{s}} \mathrm{X}^{\mathrm{s}}$ character with $c y s \mathrm{C}^{+}$confirms the presence of both uvr502 and recA56 mutations in the chromosome of KsIO7.

Construction of the uvr5ozuvrA6 double mutant, its component single mutants and the $u v r(502)^{+} u v r A^{+}$strain. Strains KSII2, KSII3, KSII4 and KSII5 are isogenic except for the $u v r A 6$ or $u v r 502$ mutations or both. The $u v r A^{+} u v r(502)^{+}$strain KSI I 2 and $u v r A 6 u v r(502)^{+}$ strain KSII 3 were constructed by co-transduction of $m e t E$ and $i v^{+}$from the strain $x 478$ into MM300 $u v r^{+}$ilvrhalacYI4thy AStrr and MM302 uvrA6 (which is isogenic to MM300 except for uvr A6) respectively.

The uvrA+uvr502 strain KSII4 and the uvrA6uvr502 strain KSII5 were obtained by 


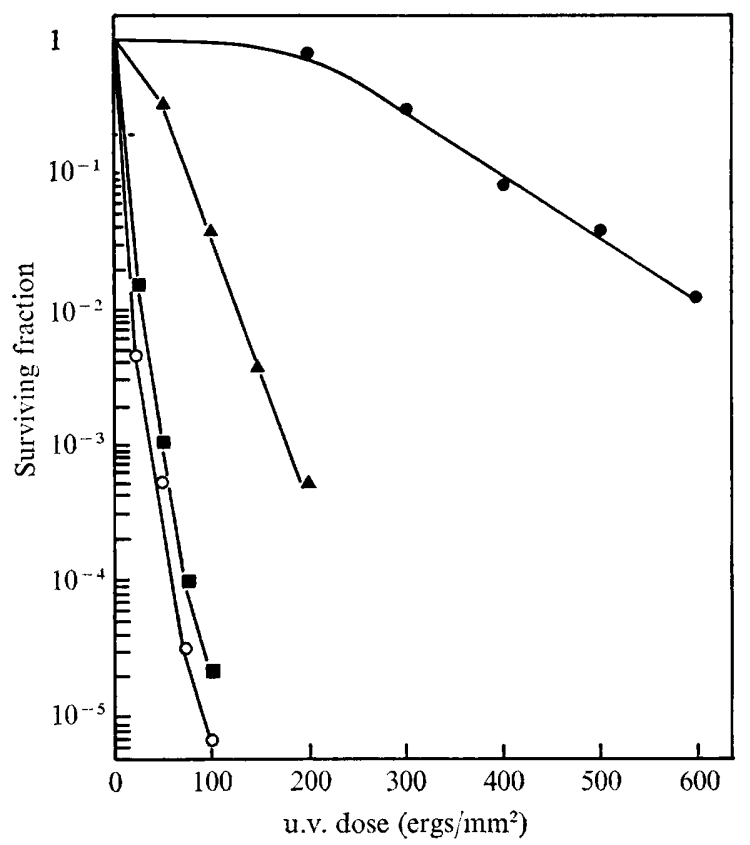

Fig. I. U.v. sensitivity of the strains $\mathrm{KsII} 2 u v r A^{+} u v r(502)^{+}(0), \operatorname{KSII} 3 u v r A 6 u v r(502)^{+}(0)$, KSII4 $u v r A^{+} u v r(502)(\Delta)$ and $\mathrm{KSII} 5$ uvrA6uvr502 (O).

co-transduction of the $u v r 502$ and metE mutations with $i l v^{+}$from the $i l v^{+} u v r 502 m e t E$ strain KS2O into the strains MM300 and MM302 respectively. The presence of the $u v r 502$ and $u v r A 6$ mutations in the chromosome of KSI 5 was confirmed by making this strain a PI donor, crossing it with the malB5 strain JGI23 or ilv strain MM300 and testing $\mathrm{Mal}^{+}$or $\mathrm{Ilv}^{+}$transductants for u.v. sensitivity. Approximately half of $\mathrm{Mal}^{+}$and $18 \%$ of $\mathrm{Ilv}^{+}$transductants obtained were UVs.

Construction of the uvr502recB2I double mutant, its component single mutants and the $u v r^{+} \mathrm{recB}^{+}$strain. The strains KSI29, KSI30, KSI3I and KSI32 are isogenic except for the uvr502 or recB2I mutations or both. The strains KSI 29 and KSI 30 were obtained in a transductional cross where the thy $A^{+} \operatorname{recB2I} \arg A^{+}$strain $\mathrm{AB} 2470$ was used as $\mathrm{PI}$ donor and the $u v r^{+}$thy $A$ rec $B^{+} \arg A$ strain $\mathrm{Ks} 60$ as a recipient. The majority of selected $\mathrm{Thy}^{+} \mathrm{Arg}^{+}$ transductants obtained in this cross were $\mathrm{UV}^{\mathrm{s}}$ and $\mathrm{X}^{\mathrm{s}}$ and one of them was designated KSI30. The $\mathrm{UV}^{r} \mathrm{X}^{\mathrm{r}} \mathrm{Thy}^{+} \mathrm{Arg}^{+}$transductant selected was designated KSI29. The strains KSI3I and KSI32 are $\mathrm{Thy}^{+} \mathrm{Arg}^{+} \mathrm{X}^{\mathrm{r}}$ and $\mathrm{Thy}^{+} \mathrm{Arg}^{+} \mathrm{X}^{\mathrm{s}}$ transductants respectively obtained in a cross of the $u v r 502 \arg A$ recB $B^{+}$thy $A$ strain KS59 (isogenic with Ks60 except uvr502) with the same PI donor AB2470.

Effects of the uvrA6, recA56 or recB2I mutations on u.v. sensitivity of the uvr502 strains

Fig. I shows u.v.-survival curves of the strains $\mathrm{KSII} 2 u v r A^{+} u v r(502)^{+}, \mathrm{KSII} 3 u v r A 6$ $u v r(502)^{+}$, KSII4 $u v r A^{+} u v r 502$ and KSII5 uvrA6uvr502. The uvr502 bacteria were about 4.6 times and the $u v r A 6$ bacteria about 15 times more u.v.-sensitive than wild-type bacteria. The uvr502 strain was therefore about 3.3 times more u.v.-resistant than $u v r A 6$ strain. The uvrA6uvr502 double mutant was only $\mathrm{I} \cdot 5$ times more u.v.-sensitive than the $u v r A 6$ single 

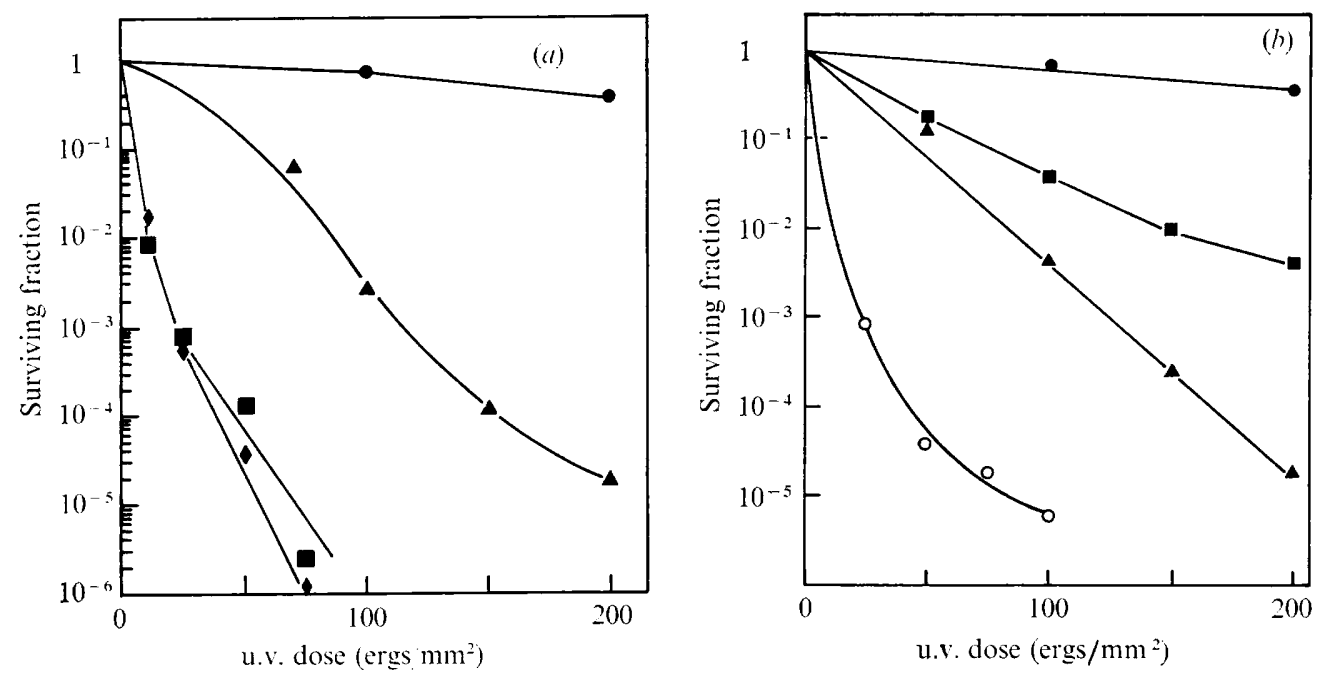

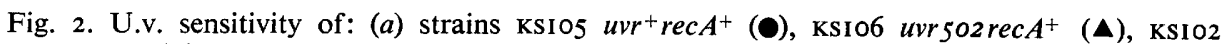

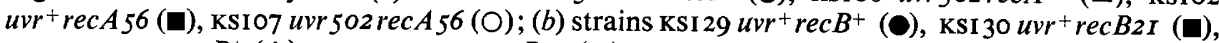
KSI3I uvr5o2 recB' $B^{+}(\Delta)$, KSI32 uvr 502 recB2I (O).

mutant. (Relative sensitivities were calculated as the ratios of the doses necessary to reduce survival by $63 \%$ in the exponential regions of the curves.)

The above result is quite different from that demonstrating the strictly additive effects of the $u v r A 6$ and $r e c A$ mutations on the u.v. sensitivity of Escherichia coli (Howard-Flanders \& Boyce, 1966) and is similar to those showing the absence of additivity of the $u v r A 6$ and resA (Kato \& Kondo, 1970) or uvrA6 and polAI (Monk, Peacey \& Gross, I97I) mutations. This suggested that the $u v r 502$ mutation, like polAI or $\operatorname{res} A$, affects the excision repair pathway and not, perhaps, the repair pathway impaired in the $\operatorname{rec} A$ mutants.

To verify this conclusion we studied the u.v. sensitivity of the double mutant uvr502 recA56 and of component single mutants and wild-type cells. Should the $u v r(502)^{+}$gene product act in the excision repair pathway then the $u v r 502$ mutation as well as $u v r A 6$ mutation ought to increase the u.v. sensitivity of the $\operatorname{rec} A$-strain. However we were surprised to find that $u v r 502$ rec $A 56$ double mutant was no more u.v.-sensitive than the single rec $A 56$ mutant (Fig. 2a). Thus the uvr502 mutation affects some repair pathway which also requires both the $u v r A^{+}$and the $\operatorname{rec} A^{+}$genes.

Fig. $2(b)$ presents u.v.-survival curves of the strains isogenic except for the uvr5o2 or recB2I mutations or both. The double mutant $u v r 502$ recB2I was much more sensitive than either the $u v r 502$ or $\operatorname{recB2I}$ mutants, indicating an additivity of the $u v r 502$ and $\operatorname{recB2I}$ mutations, i.e. $r e c B^{+}$coded products are required for a repair pathway different from that affected by the uvrsoz mutation.

Effect of the uvrA6, recA56 or recB2I mutations on spontaneous mutability of the uvr502 bacteria

Table 2 shows the spontaneous mutability of the uvr 502 mutants, wild-type bacteria and their $u v r A 6, \operatorname{rec} A 56$ or $r e c B 2 I$ derivatives. The data (of this Table) show that the frequencies of $\mathrm{Val}^{r}$ mutants in populations of the $u v r 502$ strains were much higher than those of wildtype strains. The $u v r A 6, \operatorname{rec} A 56$ or recB2I single mutants did not differ in this respect from 

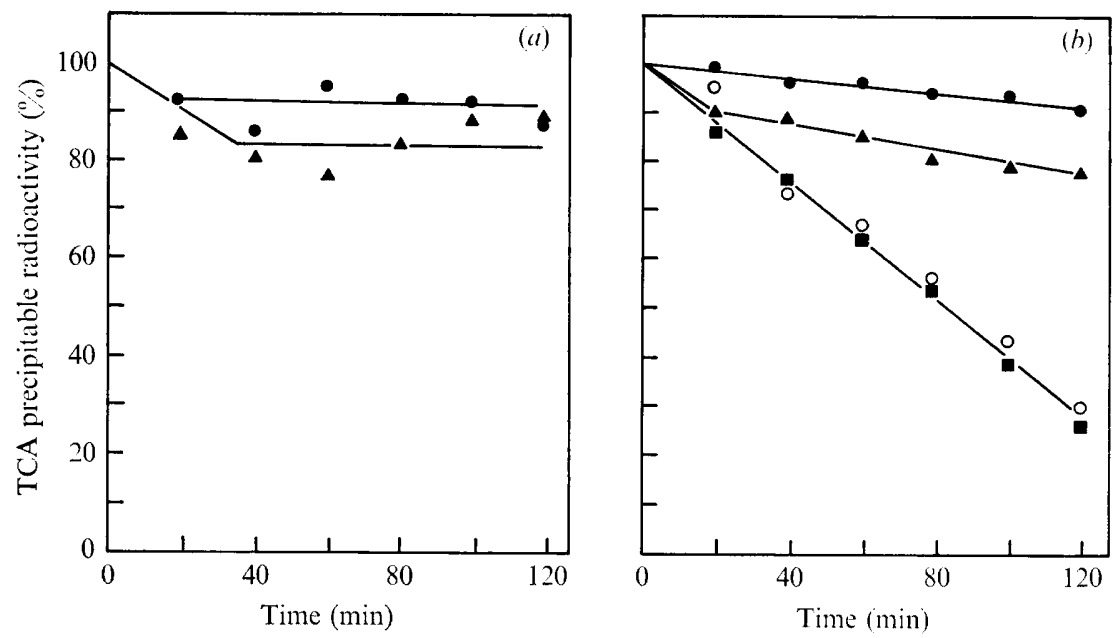

Fig. 3. Loss of acid-insoluble radioactivity from DNA of: (a) strains KSI $29 u v r^{+}(0)$ and KSI3I

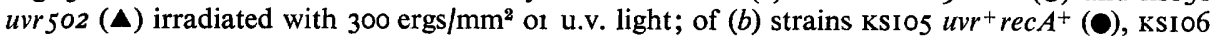

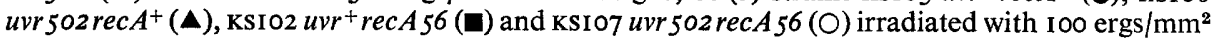
of u.v. light.

Table 2. Mutant frequencies in the populations of the uvrA6uvr502, uvr502 recA56, uvr502 recB2I double mutants, their component single mutants and wild-type strains

\begin{tabular}{|c|c|c|}
\hline Strain & Relative genotype & $\begin{array}{l}\mathrm{Val}^{r} \text { mutant } \\
\text { frequency }\end{array}$ \\
\hline KSI 12 & $u v r A^{+} u v r(502)^{+}$ & $1.6 \times 10^{-8}$ \\
\hline KSI I 3 & $u v r A 6 u v r(502)^{+}$ & $2 \times 10^{-8}$ \\
\hline KSI I 4 & $u v r A^{+} u v r 502$ & $5.3 \times 10^{-6}$ \\
\hline KSII 5 & uvrA6 uvr 502 & $4.8 \times 10^{-6}$ \\
\hline KSIO5 & $u v r^{+} r e c A^{+}$ & $8 \times 10^{-9}$ \\
\hline KSIO2 & $u v r^{+}$recA 56 & $1.4 \times 10^{-8}$ \\
\hline KSIO6 & uvr $502 \mathrm{recA}^{+}$ & $10^{-6}$ \\
\hline KSIO7 & uvr 502 rec $A 56$ & $3 \cdot 1 \times 10^{-6}$ \\
\hline KSI 29 & $u v r^{+} r e c B^{+}$ & $10^{-8}$ \\
\hline KSI 30 & $u v r^{+} r e c B 2 I$ & $10^{-8}$ \\
\hline KSI 3 I & uvr $502 \mathrm{recB}^{+}$ & $2.3 \times 10^{-6}$ \\
\hline KSI32 & uvr 502 recB2I & $5.4 \times 10^{-6}$ \\
\hline
\end{tabular}

the corresponding $u v r^{+} \mathrm{rec}^{+}$strains. The data presented in Table 2 show also that neither uvrA6 nor $\operatorname{rec} A 56$ or $\operatorname{recB2I}$ mutations reduced the mutator effect of the uvr502 mutation, suggesting that neither $u v r A^{+}$nor $r e c A^{+}$or $r e c B^{+}$gene products are involved in the formation or repair of mistakes in DNA of the $u v r 502$ or $u v r(502)^{+}$bacteria.

$D N A$ degradation in u.v.-irradiated uvr5o2 and uvr ${ }^{+}$strains and their recA56 derivatives

It was suggested above that the absence of additivity of the $u v r 502$ and recA56 mutations on the rate of u.v. killing observed in our experiments reflects the participation of the $\operatorname{rec} \mathrm{A}^{+}$ gene product in an excision repair pathway which is partly blocked by the uvr502 mutation. Since the 'reckless' type of u.v.-induced DNA degradation was found to be a characteristic property of recA mutants (Howard-Flanders \& Boyce, I966; Horii \& Suzuki, I968) we measured the extent of u.v.-induced DNA degradation in uvr502 and found that it only slightly exceeded that in the isogenic $u v r^{+}$bacteria (Fig. $3 a$ ). 
To study the effect of the uvr502 mutation on u.v.-induced DNA breakdown in rec $A$ bacteria DNA degradation was measured in the double mutant $u v r 502$ rec $A 56$, its single component mutants and wild-type bacteria (Fig. $3 b$ ). The results obtained show a similar extensive loss of acid-precipitable radioactivity from DNA of the u.v.-irradiated rec $A 56$ mutant and of uvr502 rec A56 double mutant, showing that the enzymatic DNA breakdown in u.v.-irradiated $\operatorname{rec} A$ bacteria is not affected by the uvr 502 mutation.

\section{DISCUSSION}

The data presented in this paper show that the double uvrA6uvr502 mutant is only slightly more u.v.-sensitive than the $u v r A 6$ single mutant. A possible interpretation is that the $u v r(502)^{+}$gene is responsible for some step of excision repair taking place after the incision step. However, we have not observed any additive effect of $4 v{ }^{502}$ and rec $A 56$ mutations. We suppose therefore that there exists a $u v r A^{+} r e c A^{+}$dependent repair pathway which also requires the $u v r(502)^{+}$gene product. The activity coded by the $u v r A^{+}$gene determines the ability to perform excision repair (Boyce \& Howard-Flanders, 1964) while the $\mathrm{recA}^{+}$gene product acts in postreplicative repair (Smith \& Meun, 1970) and in excision repair sequence (Monk et al. 1971; Cooper \& Hanawalt, 1972; Yonei \& Nozu, 1972). Moreover recently Bridges (1972) has postulated the existence of a third dark repair process for u.v. damage, re-initiation recovery, which may also be dependent upon both $\mathrm{recA}^{+}$and $u v r A^{+}$functions. However, we suggest that the $u v r 502$ mutation affects primarily the excision repair pathway. This suggestion was confirmed by the examination of the single-strand molecular-weight distribution of the parent and progeny DNA in u.v.-irradiated $u v r^{+}$and uvr 502 strains (Sinzinis, Saenko \& Smirnov, in preparation). The results obtained in these experiments show that the uvr50z mutation greatly reduces the joining of breaks made by incision in parent DNA strands, but not the extent of postreplicative repair.

Thus the excision repair pathway seems to require both the $u v r A^{+}$and $r e c A^{+}$genes and is most probably affected by the uvr502 mutation. We suggest that the rec $A$ and uvr502 mutations partly block the sequential linear reactions or the same reaction (if combined in a complex) of a particular step of excision repair. Inability to join interruptions resulting from dimer excision have been recently demonstrated for a recA mutant (Yonei \& Nozu, 1972). Because of the apparent role of the $r e c A^{+}$gene in repair replication (Cooper \& Hanawalt, 1972) we suggest that the $u v r 502$ and $\operatorname{rec} A$ mutations affect the resynthesis step of excision repair, which precedes final joining of single strand interruptions.

The fact that the uvr 502 bacteria are less u.v.-sensitive than $u v r A 6$ indicates that the excision repair pathway is not completely blocked in the uvr502 mutant. The possible reasons for this relative resistance are those suggested by Klein \& Niebch (197I) and Monk et al. (197I) for relatively high u.v. resistance of the polAI mutant, namely that either uvr 502 is leaky or the $u v r(502)^{+}$gene product as well as DNA polymerase I may be substituted by another enzyme. If the second is true it seems possible that DNA polymerase I may substitute for the $u v r(502)^{+}$gene product since $u v r 502$ is lethal in bacteria lacking DNA polymerase I (Mattern, I97I; Smirnov et al. 1973) as also is recA (Gross, Grunstein \& Witkin, I97I). Thus in at least one of their vital functions the $u v r(502)^{+}$and $r e c A^{+}$genes may be similar in that it may be carried out by DNA polymerase I in each case. The viability of the double mutant uvr 502 rec A56 and inviability of either polA recA (Gross et al. 197I) or polA uvr502 (Mattern, I97I; Smirnov et al. 1973) double mutants indicate that the product of neither $\operatorname{uvr}(502)^{+}$nor $\operatorname{rec} A^{+}$gene alone can substitute for DNA polymerase $\mathrm{I}$, although the latter can substitute for both simultaneously. 
The strict additivity of the effects of uvr502 and $\operatorname{rec} B 2 I$ mutations on u.v. sensitivity suggests that $\mathrm{recB}^{+}$-mediated repair acts predominantly in a repair pathway different from excision repair. Hence the $u v r 502$ mutation affects some step of the excision repair pathway in which the $\operatorname{rec} A^{+}$, but not the $\operatorname{rec} B^{+}$gene also operates.

Recently Siegel has isolated a new u.v.-sensitive mutator strain of which the mutation $m u t U r$ is recessive and mapped between $i l v$ and metE loci (Siegel, 1973). Thus the mutUI mutation described by Siegel is very similar to the $u v r 502$ mutation. In addition, the absence of additive effects of the $u v r A^{-}$and mutUr mutations on the u.v. sensitivity (Siegel, I973) suggests that the mutUr mutation as well as the uvr502 mutation affects some step of excision repair. However, the double mutant mutUr recA was more u.v.-sensitive than the single recA mutant. This implies that the mutUI affects a step of excision repair which is not defective in the recA mutant and therefore the function controlled by the mut $U^{+}$is somewhat different from that controlled by the $u v r(502)^{+}$. Possibly mut $U_{I}$ and $u v r 502$ mutations affect the different subunits or activities of the same enzyme.

In both polA and $\operatorname{rec} A$ bacteria irradiated with u.v. light the free ends of unrepaired single-strand nicks are liable to the action of exonucleases that cause an extensive DNA breakdown (Howard-Flanders \& Boyce, 1966; Paterson, Boyle \& Setlow, 1971). The mutUI mutation, which is very similar in genetic location and phenotypic effect to the uvr502 mutation, also causes increases in the rate of u.v.-induced DNA degradation when compared with mut $^{+}$(Siegel, personal communication). In contrast to these observations we have found that the extent of u.v.-induced DNA degradation in the uvr502 bacteria is only slightly greater than that in $u v r^{+}$bacteria. The result may be explained by at least two assumptions: (i) free ends of nicks made by $u v r A^{+} B^{+}$or $C^{+}$coded endonucleases in the absence of the $u v r(502)^{+}$gene product are different in chemical structure from those made in $u v r(502)^{+}$ cells; or (ii) the $u v r(502)^{+}$gene product is responsible for the modification of the ends of breaks made by $u v r A^{+} B^{+}$or $C^{+}$coded endonucleases. This modification might be necessary for the availability of the ends for hydrolysis and probably for resynthesis. However, in the double mutant uvr5ozrecA56 the rate and final extent of u.v.-induced DNA degradation was the same as in the $\operatorname{rec} A 56$ single mutant. It means that $r e c B^{+} r e c C^{+}$coded nucleases responsible for DNA degradation in u.v.-irradiated $r e c A$ bacteria (Willetts \& Clark, 1969) can also degrade DNA in the u.v.-irradiated uvr502 recA 56 double mutant. Although the behaviour of the double mutant $u v r 502$ rec $A 56$ does not confirm our assumptions it does not definitely disprove them because the absence of the $\mathrm{rec}^{+}$gene product may significantly alter the correlation of enzyme activities or the structure of breaks in the uvr502 mutant.

The increased rate of spontaneous mutagenesis (mutator effect) is another well-known property of the $u v r 502$ mutant. We have suggested that the $u v r(502)^{+}$gene product is required for fidelity of replication rather than for repair of replication errors (Smirnov, Filkova \& Skavronskaya, manuscript in preparation). In an attempt to determine the possible component of replication complex which makes mistakes in the absence of $u v r(502)^{+}$ gene product we have compared the mutant frequencies in populations of the uvr5o2 mutant and its $r e c A^{-}, r e c B^{-}$or $u v r A^{-}$derivatives. All studied double mutants showed the mutability within the range of the $u v r 502$ single mutant. The data show that neither $u v r A^{+}$ nor $\mathrm{rec} A^{+}$or $\mathrm{recB}^{+}$gene products are responsible for the mutator effect of the $u \mathrm{vr} 5 \mathrm{Oz}$ mutation. The same results were obtained in the experiments of Siegel with mutUI mutation (Siegel, 1973). 
We should like to thank Drs A. J. Clark, J. Gross, M. Monk and K. Zlotnikov for a kind gift of bacterial strains used, Drs J. K. Setlow, R. B. Setlow and P. Hanawalt for helpful discussions, and Dr E. C. Siegel, who kindly sent us information about his work before its publication.

\section{REFERENCES}

BöHME, H. (1969). In discussion in Mutation as a Cellular Process, pp. 206-209. Ciba Foundation Symposium. Edited by G. E. W. Wolstenholme and M. O'Connor. London: J. and A. Churchill.

BoycE, R. P. \& Howard-Flanders, P. (1964). Release of ultraviolet light-induced thymine dimers from DNA in E. coli K-I 2. Proceedings of the National Academy of Sciences of the United States of America $5 \mathrm{I}$, 293-300.

BRIDGES, B. A. (1972). Evidence for a further dark repair process in bacteria. Nature New Biology 240, 52-53.

COOPER, P. K. \& HANAWALT, P. C. (1972). Role of DNA polymerase I and the Rec system in excision repair in Escherichia coli. Proceedings of the National Academy of Sciences of the United States of America 65, II 56-II60.

Davis, B. \& MingIoLI, E. (1950). Mutants of Escherichia coli requiring methionine or vitamin B 12. Journal of Bacteriology 60, 17-28.

Demerec, M. E., Adelberg, E. A., Clark, A. J. \& Hartman, P. E. (1966). A proposal for a uniform nomenclature in bacterial genetics. Genetics $54,6 \mathrm{I}-76$.

DraKe, J. W. (1969). Mutagenic mechanisms. Annual Review of Genetics 3, 247-268.

Gross, J. D., Grunstein, J. \& WITKIN, E. M. (197I). Inviability of rec $A^{-}$derivatives of the DNA polymerase mutant of de Lucia and Cairns. Journal of Molecular Biology 58, 63I-634.

HoRI, Z.-I. \& SUZUKI, K. (1968). Degradation of the DNA of E. coli K-I $2 \mathrm{rec}^{-}$(JC1579b) after irradiation with ultraviolet light. Photochemistry and Photobiology 8, 93-105.

HowARD-FLANDERS, P. \& BoYCE, R. P. (I 966). DNA repair and genetic recombination: studies on mutants of Escherichia coli defective in these processes. Radiation Research Supplement 6, 156-184.

KATO, T. \& KoNDO, S. (1970). Genetic and molecular characteristics of X-ray-sensitive mutants of Escherichia coli defective in repair synthesis. Journal of Bacteriology 104, 87I-88I.

KLeIN, A. \& NIEBCH, U. (I97I). Host cell reactivation in strains of $E$. coli lacking DNA polymerase activity in vitro. Nature New Biology 229, 82-84.

LIBERFARB, R. M. \& BRYSON, V. (1970). Isolation, characterization and genetic analysis of mutator genes in Escherichia coli B and K-I 2. Journal of Bacteriology 104, 363-375.

MATtern, I. E. (197I). A class of UV-sensitive mutants of E. coli K-I 2 that show a high spontaneous mutation frequency. In First European Biophysics Congress, pp. 237-240. Edited by E. Broda, A. Locker and $\mathrm{H}$. Springer-Lederer.

Monk, M., PeACeY, M. \& Gross, J. D. (1971). Repair of damage induced by ultraviolet light in DNA polymerase-defective Escherichia coli cells. Journal of Molecular Biology 58, 623-530.

Paterson, M. C., Boyle, J. M. \& Setlow, R. B. (197I). Ultraviolet and X-ray-induced responses of a deoxyribonucleic acid polymerase-deficient mutant of Escherichia coli. Journal of Bacteriology 1o7, $6 \mathrm{I}-67$.

SiEgel, E. C. (1973). Ultraviolet-sensitive mutator of Escherichia coli K-I 2. Journal of Bacteriology II3, I45-I60.

Smirnov, G. B., Filkova, E. V. \& Skavronskaya, A. G. (1972). The mutator property of uvr502 mutation affecting UV-sensitivity of Escherichia coli. Molecular and General Genetics 118, $51-56$.

Smirnov, G. B., Filkova, E. V., Skavronskaya, A. G., Saenko, A. S. \& Sinzinis, B. I., (1973). Loss and restoration of viability of $E$. coli due to combinations of mutations affecting DNA polymerase I and repair activities. Molecular and General Genetics, I21, 139-150.

Smirnov, G. B. \& Skavronskaya, A. G. (1968). The lethal and mutagenic action of UV-light and mitomycin C on the mutants of Escherichia coli with reduced dark repair ability. Genetika (USSR) 4, 105-1 10.

Smirnov, G. B. \& SkaVronskaya, A. G. (I971). Location of uvr502 mutation on the chromosome of Escherichia coli K-I 2. Molecular and General Genetics I13, $217-221$.

SмITH, K. C. \& MeUN, D. H. C. (1970). Repair of radiation-induced damage in Escherichia coli. I. Effect of rec mutations on postreplication repair of damage due to ultraviolet radiation. Journal of Molecular Biology 5I, 459-472.

TAYLOR, A. L. (1970). Current linkage map of Escherichia coli. Bacteriological Reviews 34, 155-175. 
Willetts, N. S. \& ClARK, A. J. (1969). Characteristics of some multiply recombination-deficient strains of Escherichia coli. Journal of Bacteriology roo, 23I-239.

YoNEI, S. \& NozU, K. (1972). Mechanism of postirradiation degradation of deoxyribonucleic acid in a radiosensitive Escherichia coli (NG 30) irradiated with ultraviolet light. Journal of Molecular Biology 65, 213-225. 